\title{
Learning in Early Childhood
}

\section{Introduction}

There is a widespread consensus that the first five or six years of life are particularly important for children's learning. There is evidence of rapid growth and learning from a range of disciplines, charting changes in physical, social, emotional and cognitive capacities. From neuroscience we learn about changes in the brain that speed up the passage of signals and increase the number of synaptic connections. Psychologists have identified changes in children's cognitive capacities in the early years of life e.g. becoming able to sort, classify, sequence and use symbols, the development of meta-cognition and theory of mind. From a sociological perspective learning in the early years is often seen as a process of enculturation as children learn the ways of their families and society. But they do not just learn how to 'fit in', they appropriate, reinvent and contribute to cultural reproduction (Corsaro, 1997).

The focus in this chapter is on the learning of 3- to 5-year olds, often referred to as the pre-school years. This is not to suggest that children younger than 3 years old do not learn - they clearly do. There is a wealth of literature which demonstrates that babies learn from birth and that some kinds of learning occur in the womb (e.g. Goswami, 2008). Infants learn through tracking associations between co-occuring events, imitation, constructing causal connections and making analogies. The focus on 3-5-year olds is a response to pragmatic considerations about space in this brief chapter but it is also in recognition of the distinctive nature of the ways in which young children learn as they begin to engage more independently with the world outside their homes and with settings designed to foster their development. As Nelson (1996, p 325) points out

Between about 2 and 6 years of age language and the surrounding culture take over the human mind. It is during these years that biology "hands over" development to the social world.

This chapter will look at the ways in which learning in the early years has been theorised and at the understandings that have shaped the educational provision made for young learners and the practices they experience in these settings.

Learning is an internal process made evident in changes in children's level of skill, confidence and knowledge. At nursery children's actions demonstrate that they have learned, for instance, how to share with others or have mastered one to one correspondence counting. At home they move from depending on adults for their basic needs to washing, dressing and eating independently. Learning is a pervasive feature of the lives of preschool children. They can learn at home, out of doors, in educational settings and with others or alone. They learn

- how to do things

- about how things work and the world around them

- about communications and relationships

In addition, they learn how to learn and develop dispositions that support their potential to learn such as persistence, co-operation, independence and confidence. Learning in early childhood 
involves the acquisition of skills, practices and more abstract knowledge and it happens across the physical, social, cognitive, communication and emotional spheres of children's lives. For some learning is regarded as synonymous with development, but while most children share a common developmental pattern they do not all learn the same things at the same time or acquire the same skills.

In this chapter learning is conceived as a socio-cultural process that is the product of physical, social, cultural and environmental experiences, as well as individual biological development. The focus is on the processes that are associated with learning, rather than giving an account of what is typically learned during the preschool years. The chapter begins with an examination of recent findings from neuroscience and cognitive psychology before moving on to the classic theories of Piaget and Vygotsky which have been so influential in early years education. A review of work on learning at home and in preschool settings follows. The final section of the chapter looks at the relationship between play and learning in early childhood.

\section{From neuroscience and cognitive psychology}

At birth parts of the human brain have almost all the brain cells they will ever have while the number of cells in other areas e.g. the cerebellum and hippocampus, grows rapidly in the first year of life. The number of connections between brain cells also increases dramatically in the first 12 months, followed by pruning so that frequently used connections are strengthened and infrequently used links are removed. As our understanding about the human brain develops there has been a tendency to look to neuroscience for answers to questions about facilitating cognitive growth. However, despite the claims of some policymakers and politicians, neuroscientists suggest that there is no convincing evidence for beginning formal education as early as possible (Blakemore and Frith, 2005). Much of our knowledge about changes in the brain in the early years comes from animal studies and it would be inappropriate to assume that the time course for the proliferation and pruning of synaptic connections is the same in humans as it is for other species. Furthermore, synaptic connections in the human brain develop at different rates: in the visual cortex they reach a peak at about 10 months old while in the frontal cortex (responsible for planning and decision-making) growth in synaptic density starts later and pruning begins in adolescence.

For human beings interaction, language and communication with other humans is important for later development. Work in cognitive psychology has charted the mastery (between two and six years old) of the sounds, vocabulary and grammar which allows children to learn through interactions with others. Babies seem to be predisposed to attend to other people and engage in social interactions which are a powerful source of learning opportunities. Their brains are ready to understand and learn through language from an early age and the social mediation of learning in young children is not limited to cognitive and socio-emotional domains; perceptual learning is also supported by social interaction. Current thinking discounts ideas about rigid 'critical periods' when particular stimulation is needed to develop certain sensory or motor systems. Neuroscientists now argue instead for sensitive periods when the kind of stimulation needed for normal development is present in the everyday environment of the organism. Evidence about the negative impact of growing up alone and without stimulating 'toys' comes mainly from studies of rats. While this work demonstrates the negative impact of deprived environments Blakemore and Frith $(2005, \mathrm{p} 33)$ conclude that ' $[\mathrm{i}] \mathrm{t}$ is 
unlikely that children brought up in any "normal" child-orientated environment could be deprived of sensory input.'

Evidence from cognitive psychology suggests that children can reason in the same way as adults and can learn from imitation and analogy but that their lack of experience can limit their thinking. Neuroscience research has revealed that learning depends on the establishment of multi-sensory networks of neurons across the brain so that activity in neurons in several areas such as memory and spatial may be associated with one concept. Goswami and Bryant (2007) argue that because of this distribution of representations across networks cumulative experiences and multi-sensory approaches make an important contribution to learning. They go on to point out that popular notions such as left or right brain learning or uni-sensory 'learning styles' are not supported by neuroscience.

\section{Theories of learning}

Two theories about learning have been particularly influential when considering early childhood: the work of Jean Piaget and of Leo Vygotsky. Both began publishing their work in the 1920's. Piaget's work was widely available in French and English from that period (e.g. 1926, 1929) but Vygotsky's work was not readily available in English until the 1960's and 70's (e.g. 1962, 1978). As a result Piaget's stage theory of development was the dominant perspective on learning and knowing in early childhood for much of the $20^{\text {th }}$ century.

Piaget conceptualised learning as a product of either assimilation or accommodation, both of which result in changes in the mental structures by which children make sense of the world. If a child's current mental structures allow her to make satisfactory sense of the new information then it is assimilated and equilibrium is maintained. On the other hand, if a child's encounters information that she cannot make sense of with her existing mental structures then disequilibrium is experienced and the structures are changed through a process of accommodation until a new equilibrium is reached. For Piaget the drive to achieve equilibrium is what powers intellectual growth; it is the enduring curiosity that compels children to seek to understand all that they encounter.

Fundamental to Piaget's theory of knowledge growth is that it happens in a step-wise, linear and unidirectional manner. Piaget argued that from about 2 years of age preoperational thought replaces the earlier sensori-motor period and continues until about the age of 7 when the stage of concrete operations is reached. In the preoperational stage children are freed from their previous dependence on physical realities and are able to make sense of the world through symbols such as words or images. They are able to distinguish fantasy from 'reality' and can take part in imaginative activities. However, Piaget's original construction of the preoperational stage saw 2-6 year olds as egocentric and unable to take account of the perspectives of others, as being unable to reverse sequences and of pre-logical thinking.

Piaget's work has been subject to extensive critique and modification by later researchers (e.g. Donaldson, 1978). It has been widely criticised as suggesting a deficit model of children (focusing on what they cannot do compared to adults) and as normative and wrongly focused on notions of individual development irrespective of the context in which children are growing up (e.g. James, Jenks and Prout, 1998; Burman, 1994). Nevertheless, it has retained a significant implicit and explicit influence on educational practices in the early years. This legacy can be seen in the attention to 
defined age groups and staged expectations in curricula, in age differentiated groups of children in one setting and in the provision of a resource-rich environment designed to offer novel experiences and stimulate exploration in order to challenge and develop children's mental structures. It is present too in thinking that sees the role of preschool practitioners as being to arrange the learning environment then remain 'in the background', allowing the child to be a 'lone explorer' (Stephen, 2010). However, despite the critiques and caveats Piaget's theory has made an important contribution through the attention which it has focused on young children's drive to explore and make sense of their physical and social environment and actively construct their knowledge through assimilation and accommodation. As a result we have become aware that it cannot be assumed that a young child makes sense of the world in the same way as any particular older child or adult and, therefore, of the pedagogic imperative to understand the individual's perspective in any learning interaction or activity.

Vygotsky also saw children as active participants in learning, However, he conceptualised the learning process as one in which children acquire the cultural tools of their society (such as language, mathematical concepts) through their interactions with adults or more able peers. According to Vygotsky children learn first through interactions with others, moving on over time to be able to carry out the operations they previously did together with internal guidance alone - a shift from joint thinking and supported understanding to individual competencies, knowledge and independent attainment. What is usually translated as the Zone of Proximal Development captures this progression from what is currently known to what can be understood or achieved with the help of another. Schaffer $(2004, \mathrm{p} 216)$ claims that

[Vygotsky's] principal achievement was to have shown the gains to be made in our understanding when children are treated as part of the 'social world' and not detached from their environmental context.

Vygotsky's ideas give rise to particular implications for parents and preschool practitioners as they seek to facilitate young children's learning. Here the role of the adult or more capable other is to be aware of what a child can do alone and, through joint activity and talk, to assist the learner to move beyond previous achievements. This adult support for young children's learning was conceptualised by Wood et al (1976) as scaffolding. They noted how mothers of 3- to 4-year olds offered help with a block building task in ways that allowed the children to learn to complete the activity independently. The help which the mothers offered was predominantly, though not exclusively, mediated through language and was implicitly contingent on the children's progress. They offered more help when they noticed that the child was experiencing difficulties and reduced their involvement when it was not needed.

Other studies have followed, aimed at articulating the particular characteristics of effective scaffolding (e.g. Saxe, Guberman and Gearhart, 1987). A study of the support need to enhance preschool children's encounters with new technologies (such as computer games and digital cameras) found that both proximal and distal actions on the part of preschool practitioners made a difference to children's engagement with the learning opportunities offered by the technology (Stephen and Plowman, 2008). Distal actions included planning and making decisions about resources. Effective proximal guided interaction or scaffolding was multi-modal. Physical help, 
demonstrations by adults, verbal feedback, reading written instructions and emotional support such as praise or being alongside during a time of anxiety all sustained engagement.

Nelson (1996) argued that neither Piaget's individual construction model nor Vygotsky's social construction model was an adequate explanation of the process of children's learning. She suggested that what was needed was a model that construed individuals as constructing understandings and representations in collaboration with social others. She saw children as shifting from individual, experiential representations to everyday or folk understandings, mediated through language and acquired informally through contact with their families and community. They are followed later by understandings that are formal, organized and abstract and which are explicitly taught in the course of formal education, rather than 'caught' in the course of everyday living.

\section{'Everyday learning'}

Rogoff (2003) has explored learning as a cultural activity. Starting from a socio-cultural position which rejects universal claims about stages of development she argued that what, when and how children learn is influenced by the social and cultural circumstances in which they live. Rogoff considered the kind of learning interactions that occur in the Zone of Proximal Development as being primarily associated with formal learning situations. She turned her attention instead to the everyday interactions that happen in families and communities and which, although not designed to teach or engender learning, provide children with important opportunities to acquire the tools and practices of their culture.

Rogoff conceptualised this process of learning in informal and everyday settings as guided participation. This concept arose from investigations of the learning interactions of mothers and young children in four very different cultural settings (Rogoff et al, 1993). They identified two distinct components to guided participation. The first of these is mutual bridging of meanings. Young children and their carers and siblings use the cultural tools of language, gesture and referencing of actions and reactions to establish a shared understanding in order to be able to act together. The second basic component of guided participation is described as the mutual structuring of participation. Children and adults are involved in the structuring of activities, choosing what to engage in, what should be observed and who to interact with. For instance, parents position items they wish young children to learn to use so that they are accessible, break down tasks into more manageable stages and recount and elaborate narratives which serve to instruct about local practices.

But children too influence what is learned. Their preferences make a difference to the activities and family and community practices with which they choose to engage. Stephen et al (2008) found that having access to technology at home and parents and siblings who were enthusiastic about using domestic and leisure technologies was not enough to encourage some four- and five-year olds to, for example, play computer games, or master selecting television channels. Brooker (2002) found that children growing up in culturally different homes located in one geographical area had very different learning outcomes before they went to school as a result of the opportunities available and the practices to which they were introduced. Children in the disadvantaged English-heritage families were introduced to play with dough, Lego and paint at home before they went to school and could move readily to make use of these resources when they entered the first class at school. Four-year olds from the Bangladeshi-heritage homes were less likely to have experiences of play with such 
'educational' resources but they were often skilled participants in other aspects of everyday life such as food preparation.

The Effective Provision of Pre-school Education (EPPE) project has examined the contribution that family socio-economic circumstances, the activities that children take part in at home and the educational provision offered in group settings make to later attainment. The researchers found that children's Home Learning Environment made a difference to their later academic attainment and social development (Melhuish et al, 2008). The Home Learning Environment index is compiled from parent's accounts of engaging in specific learning activities such as, reading with their child, singing songs and rhymes, visiting the library. What parents did with their children at home made a significant difference to later attainment in reading and mathematics, even after five years of primary school.

\section{Learning in early childhood educational settings}

There is a wealth of literature offering evidence about the positive association between attending good quality preschool provision and children's learning (e.g. Schweinhart and Weikart, 1997; Currie, 2001). In England the longitudinal Effective Provision of Preschool Education study has demonstrated that attending preschool provision enhances children's attainment on a range of measures of cognitive development (e.g. reading and mathematics) and social development (e.g. concentration, independence, anti-social/worried behaviour), regardless of home and family socio-economic circumstances (Sammons et al, 2004). The benefits of good quality early years education were still evident at age 7 and at age 10 (Sylva et al, 2010). However, the EPPE findings make it clear that the quality of preschool settings varies and that not all provision makes the same level of contribution to children's future attainment. At preschool settings that were more effective at adding value to children's learning practitioners had good curriculum knowledge as well as an understanding of child development and offered children a balance of freely chosen but 'potentially instructive' activities and teacher-initiated and teacher-led group work. In the most effective settings adult-child interactions were characterised by 'sustained shared thinking' between adults and children and open-ended questioning to extend children's exploration and reasoning (Siraj-Blatchford and Sylva, 2004).

The evidence from studies of learning at home and in preschool makes clear the important role of adults in supporting children's learning through the environments they provide, the scaffolding they offer and the thinking and meaning-making they prompt. Drawing conclusions from their authoritative review of the research about the ways in which two- to five-year olds learn Bowman et al point out that

Research from a variety of theoretical perspectives suggests that a defining feature of a supportive environment is a responsible and responsive adult. (Bowman et al, 2000, p 5)

New thinking about the ways that the social and the material environment shape learning conceptualises it as happening in between the resources, the learner and others adults and children (Lenz Taguchi, 2010). Olsson (2009) too focuses on interactions in the learning context. She argues for an approach to learning that makes space for children's desires and interests, works with potential and immanence and follows 'lines of flight'. Both these ways of 
theorising learning see adults as important but they require them to be open to the unexpected and to learn to 'surf it'.

\section{Play and learning}

Along with the emphasis on 'child-led' learning activities, play is one of the 'big ideas' of preschool education and any account of learning in the preschool years must consider the role of play. 'Learning through play' is a core element in the consensus position and formal guidance on appropriate educational provision for 2- to 5 -year olds in UK and in countries influenced by guidance on Developmentally Appropriate Practice (NAEYC, 2009). The emphasis on experiential, child-led play was present in the approach of the pioneers of early childhood education such as Susan Issacs who argued that 'play has the greatest value for the young child when it is really free and his own' (Issacs, 1932, p 133). Nevertheless, despite its long association with learning in the early years play is under-theorized and under-researched and the efficacy of play is more often asserted than evidenced (BERA Early Years SIG, 2003).

The work of Vygotsky and post-Vygotskian researchers theorises play as a 'leading factor in development' and a particular feature of the preschool period (Vygotsky, 1976). They argue that during the preschool years play is the medium for the child's exploration of the world, a bridge between creating understandings mediated through actions and the later development around five years old of abstract and symbolic or 'schooled' thinking. However, by play Vygotsky meant play that meet specific criteria: children creating an imaginary situation, acting out roles and following rules determined by those roles (Bodrova, 2008). Such play they argued allows children to progressively separate the real, imaginary and symbolic. But Fleer (2010) has demonstrated that play episodes do not always develop the kind of conceptual understanding that practitioners intend. She suggests that play needs careful framing if it is to be used as a pedagogic tool to support abstract concept formation.

From the perspective of socio-cultural theory then play is considered to be the driver for a distinct stage of cognitive development and refers to particular kinds of imaginary activities. However, policy documents often refer to an undifferentiated notion of play and educators attempt to appropriate children's desire to play as a way to engage them in the adult's agenda, without considering whether this negates the apparent benefits. For example, curriculum guidance in Scotland refers to the advantages conferred by 'spontaneous play' and 'planned purposeful play' while in Wales play is referred to as a 'serious business' which is important for intellectual and social development. Sutton Smith (1997) refers to this as the rhetoric of progress associated with play and, declaring his scepticism about the over-generalised claims for the developmental power of play, he concludes that play is 'seldom to be the only determinant of any of the important forms of learning that occur in young children' (1997, p 41).

An alternative view of play is as cultural activity, reflecting the cultural traditions and the economic, communicative and value contexts in which children live (Göncü et al, 2006). Others have written about play as a means of exploring and developing identity, developing friendships and as a space to resist adult structures and intentions (e.g. Rogers and Evans, 2008). The relationship between play and learning outcomes must remain on the agenda for further research. In there is clearly scope for future exploration to look at what adults and children consider to be play and playful, at the ecology or context of play at home and in educational settings and at what is played and what is learned. 


\section{In conclusion}

There can be no firm conclusions about learning and the processes associated with learning in early childhood other than that it is contingent. What children learn in early childhood depends on their interests and the cultural practices, values and expectations of the environments in which they grow up. Learning always takes place in particular contexts which will influence the opportunities offered and the learning that occurs. Ideas about what it is important to learn vary across families and cultures and, in settings funded by the state, practices will reflect policy objectives. Across the range of theoretical perspectives on the process of learning reviewed two characteristics stand out. Firstly, young children are active agents in their own learning; across the domains learning is not a process of transmission but one of construction and sense-making. And the second is that the support of other adults and children is an essential component of the learning process. Through the mediation of others children acquire the cultural tools of their society and become able to participate in its practices. Language is a critical channel for this mediation but learning is supported by multi-modal forms of scaffolding.

Much more remains to be explored about the process of learning in early childhood. For example, neuroscience holds out the promise of further understandings about the possibilities for and limitations on learning. There is a need to continue to investigate the relationship between play and learning and the influence of the material world as well as the social and emotional contexts in which learning takes place and consider the implications of this research for pedagogical practices. There are new and emerging challenges too. Yelland et al (2008) have called for attention to be paid to the kinds of competencies and knowledge that will be needed for the $21^{\text {st }}$ century, raising questions about the kind of learning will be valued in the future and how this learning can be supported now. And some challenges are enduring. A growing body of research points to the considerable influence of family background (e.g. socio-economic status, parents' educational background) on later attainment. If we are to 'close the gap' there is much more to be understood about ways of supporting, at home and in educational settings, the learning of young children who grow up in disadvantageous circumstances.

\section{References}

Blakemore, S-J. and Frith, U. (2005) The learning brain: lessons for education. Oxford: Blackwell Publishing.

Bodrova, E. (2008) Make-believe play versus academic skills: a Vygotskian approach to today's dilemma of early childhood education. European Early Childhood Education Research Journal. 16, 3: 357-370.

Bowman, B. T., Donovan, M.S. and Burns, M.S. (2000) Eager to Learn: Education Our Preschoolers. Washington, DC: National Academic Press.

British Educational Research Association (BERA) Early Years Special Interest Group (2003) Early Years Research: Pedagogy, Curriculum and Adult Roles, Training and Professionalism http://www.bera.ac.uk/files/2008/09/beraearlyyearsreview31may03.pdf

Brooker, L. (2002) Starting School: Young Children Learning Cultures. Buckingham: Open University Press. 
Burman, E. (1994) Deconstructing Developmental Psychology. London: Routledge.

Corsaro, W. A. (1997) The Sociology of Childhood. Thousand Oaks: Pine Forge Press.

Currie J. (2001) Early Childhood Education Programs. Journal of Economic Perspectives 15,2,Spring: 213-238.

Donaldson, M. 1978. Children's Minds. London: Fontana.

Fleer, M. (2010) Conceptual and contextual intersubjectivity for affording concept formation in children's play. In L. Brooker and Susan Edwards (eds.) Engaging Play. Maidenhead: Open University Press.

Goswami, U. (2008) Cognitive Development - The Learning Brain. Hove: Psychology Press.

Goswami, U. and Bryant, P. (2007) Children's Cognitive Development and Learning (Primary Review Research Survey 2/1a). Cambridge: University of Cambridge Faculty of Education. Available at http://www.primaryreview.org.uk/Publications/Publicationshome.html

Göncü, A., Jain, J. and Tuermer, U. (2006) Children's Play as Cultural Interpretation. In A Göncü and S Gaskins (eds.) Play and Development: Evolutionary, Sociocultural and Functional Perspective. Mahwah NJ: Lawrence Erlbaum.

Isaacs, S. (1932) The Nursery Years. London: Routledge and Kegan Paul.

James, A., Jenks, C. and Prout, A. (1998) Theorizing Childhood. Cambridge: Polity Press.

Lenz Taguchi, H. (2010) Going Beyond theTheory/Practice Divide in Early Childhood Education: Introducing an intra-active pedagogy. Abingdon: Routledge.

Melhuish, E.C., Sylva, K., Sammons, P., Siraj-Blatchford, I., Taggart, B., and \& Phan, M (2008) Effects of the Home Learning Environment and preschool center experience upon literacy and numeracy development in early primary school. Journal of Social Issues 6: 157-188.

National Association for the Education of Young Children (NAEYC)(2009) Developmentally Appropriate Practice, $3^{\text {rd }}$ edition. Washington: NAEYC. Available at http://www.naeyc.org/DAP

Nelson, K. (1996) Language in cognitive development: emergence of the mediated mind. Cambridge NY: Cambridge University Press.

Olsson , L. M. (2009) Movement and Experimentation in Young Children's Learning: Deluze and Guattari in early childhood education. Abingdon: Routledge.

Piaget, J. (1926) Judgement and Reasoning in the Child. New York: Harcourt Brace Jovanovich.

Piaget, J. (1929) The Child's Conception of the World. New York: Harcourt Brace Jovanovich.

Rogers, S. and Evans, J. (2008) Inside Role-Play in Early Childhood Education. Abingdon: Routledge.

Rogoff, B. (2003) The Cultural Nature of Human Development. Oxford: Oxford University Press. 
Rogoff, B., Mistry, J., Göncü, A. and Mosier, c. (1993) Guided participation in cultural activity by toddlers and caregivers. Monographs of the Society for Research in Child Development. 58, 7 no 236.

Sammons, P., Elliot, K., Sylva, K., Melhuish, E., Siraj-Blatchford, I. and Taggart, B. (2004) The impact of pre-school on young children's cognitive attainments at entry to reception. British Educational Research Journal. 30, 5: 691-712.

Saxe G.B., Guberman, S. R. and Gearhart, M. (1987) Social processes in early number development. Monographs of the Society for Research in Child Development, 52, (2, Serial No. 216).

Schaffer, H. R. (2004) Introducing Child Psychology. Oxford: Blackwell Publishing.

Schweinhart L. J. \& Weikart D. P. (1997) Lasting Differences: The High/Scope ${ }^{\circledR}$ Preschool Curriculum Comparison Study through Age 23. Monographs of the High/Scope ${ }^{\circledR}$ Educational Research Foundation. Ypsilanti, MI: High/Scope ${ }^{\circledR}$ Press.

Siraj-Blatchford, I. and Sylva, K. (2004) Researching pedagogy in English pre-schools. British Educational Research Journal. 30, 5: 713- 730.

Stephen, C. (2010) Pedagogy: the silent partner in early years learning. Early Years, 30: 1, 15-28.

Stephen, C. and Plowman, L. (2008) Enhancing learning with information and communication technologies in pre-school. Early Child Development and Care 178, 6: 637-654.

Stephen, C., McPake, J., Plowman, L. and Berch-Heyman, S. (2008) Learning from the Children: Exploring Preschool Children's Encounters with ICT at Home. Journal of Early Childhood Research 6, 2: 99-117.

Sutton Smith, B. (1997) The ambiguity of play. Cambridge: MA: Harvard University Press.

Sylva, K., Melhuish, E., Sammons, P. and Siraj-Blatchford, I. (2010) Early Childhood Matters: evidence from the effective pre-school and primary education project. Abingdon: Routledge.

Vygotsky, L.S. (1962) Thought and Language. Cambridge, MA: M.I.T. Press.

Vygotsky, L.S. (1976) Play and its role in the Mental Development of the Child. In J. Bruner, A. Jolly, and K. Sylva (eds.) Play - Its role in development and evolution. p 537 - 554. Harmondsworth: Penguin.

Vygotsky, L. S. (1978) Mind in Society. Cambridge, MA: Harvard University Press.

Wood, D., Bruner, J. and Ross, G. (1976) The role of tutoring in problem solving. Journal of Child Psychology and Psychiatry 17: 89-100.

Yelland, N., Lee. L., O'Rouke, M. and Harrison, C. (2008) Rethinking Learning in Early Childhood Education. Maidenhead: Open University Press. 